\title{
Synthesis of Block Copolymer Segments Containing Different Ratios of Ethylene and 5-Norbornen-2-yl Acetate
}

\author{
Steve J. Diamanti', Vikram Khanna ${ }^{\dagger}$, Atsushi Hotta ${ }^{\dagger}$, Diane Yamakawa ${ }^{\dagger}$, \\ Fumihiko Shimizu ${ }^{\ddagger}$, Edward J. Kramer ${ }^{\dagger *}$, Glenn H. Fredrickson ${ }^{\dagger}$, and \\ Guillermo C. Bazan ${ }^{\dagger *}$ \\ †Institute for Polymers and Organic Solids and Mitsubishi \\ Chemical Center for Advanced Materials, Departments of \\ Chemistry and Materials, University of California, Santa Barbara, \\ California 93106 \\ $\$$ Mitsubishi Chemical Corporation, Science and \\ Technology Research Center, 1000 Kamoshida-Cho, Aoba-Ku, \\ Yokohama 227-8502, Japan.
}

General Remarks: All manipulations were performed under an inert atmosphere using standard glove box and Schlenk techniques. All reagents were used as received from Aldrich unless otherwise specified. A Parr $100 \mathrm{~mL}$ metal reactor (model 4565) was used for all polymerizations. Ethylene was from Matheson Tri-Gas (research grade, 99.99\% pure) and was purified by passage through high pressure, stainless steel, oxygen and moisture traps (Matheson models OT-4-SS and MT-4-SS respectively). Toluene, THF, hexane and pentane were distilled from benzophenone ketyl. Toluene for polymerization runs was distilled from sodium/potassium alloy. [N-(2,6-diisopropylphenyl)-2-(2,6diisopropylphenylimino)propanamide] $\mathrm{Ni}\left(\mathrm{CH}_{2} \mathrm{Ph}\right)\left(\mathrm{PMe}_{3}\right)$ (2) and $\mathrm{Ni}(\mathrm{COD})_{2}$ were synthesized as reported previously ${ }^{1}$ and purified by re-crystallization prior to polymerization use. NMR spectra were obtained using a Varian Unity 400 or 500 spectrometer. ${ }^{1} \mathrm{H}$ NMR spectra of the polymers were obtained in mixed solvent $\left(\mathrm{C}_{6} \mathrm{D}_{6} / 1,2,4\right.$-trichlorobenzene $1: 4$ ratio in volume $)$ at $115^{\circ} \mathrm{C}$.

Gel Permeation Chromatography Analysis (GPC): GPC measurements were performed on a Polymer Labs High Temperature GPC system (Model PL-220). All 
samples were run at $135^{\circ} \mathrm{C}$ in o-dichlorobenzene with BHT (0.5g BHT/ 1L odichlorobenzene) added as a radical scavenger. Runs were performed at a run rate of 1.0 $\mathrm{mL} / \mathrm{min}$. for 40 minutes. Samples were prepared at a concentration of $2.0 \mathrm{mg}$ polymer / $1.0 \mathrm{~mL}$ solvent. $3 \mathrm{PL}$ mixed-B columns were used in series. Polymer detection was by a Differential Refractive Index Detector. Molecular weights were calculated by universal calibration from narrow molecular weight distributions polystyrene standards. PL-Cirrus was the software interface.

Differential Scanning Calorimetry: Differential scanning calorimetry was used to determine the thermal characteristics of the copolymers using a TA Instruments DSC 2920. The DSC measurements were recorded during the second heating/cooling cycle in the $-10^{\circ} \mathrm{C}$ to $180^{\circ} \mathrm{C}$ range at a rate of $5^{\circ} \mathrm{C} / \mathrm{min}$. Each sample for DSC was approximately 5 to $10 \mathrm{mg}$. The glass transition temperature $\left(\mathrm{T}_{\mathrm{g}}\right)$, the crystallization temperature $\left(\mathrm{T}_{\mathrm{c}}\right)$, the melting point $\left(\mathrm{T}_{\mathrm{m}}\right)$ and the heat of fusion $\left(\mathrm{H}_{\mathrm{m}}\right)$ of the materials were determined in this way.

Transmission Electron Microscopy: Bulk polymer samples were annealed in high vacuum for 1 day at $200^{\circ} \mathrm{C}$, followed by 3 days at $160^{\circ} \mathrm{C}$ to allow the microphase to equilibrate, followed by a rapid quench in $<1$ min to liquid nitrogen temperatures. First the sample surface was cut at $-190^{\circ} \mathrm{C}$ to make a smooth surface for the stain to penetrate into the sample. The sample was then stained in the vapor of a $0.5 \% \mathrm{RuO}_{4}$ stabilized aqueous solution (Electron Microscopy Science) for a period of five days. Sections 80 $\mathrm{nm}$ thick of the stained polymer were then cut using a Leica Ultracut UCT ultramicrotome with a diamond knife at room temperature. TEM images of the stained samples were obtained using a FEI Tecnai G2 Sphera TEM operating at $200 \mathrm{kV}$. The observed contrast is due to the local oxidation of the amorphous phase of the block copolymer by $\mathrm{RuO}_{4}$.

Atomic Force Microscopy: Atomic force microscopy studies were performed on annealed block copolymer films. The films were spuncast from hot decahydronapthalene solutions (3 wt\%) on hot Si substrates at $2200 \mathrm{rpm}$. The spuncast films were then 
annealed in high vaccum $\left(<10^{-7}\right.$ mbar $)$ at $200^{\circ} \mathrm{C}$ for 1 day and $160^{\circ} \mathrm{C}$ for 3 days. The films were subsequently imaged using a Digital Instruments Multi-mode Nanoscope. The imaging was performed in tapping mode. The attached AFM images in phase contrast depicting the block copolymer morphology are attached.

Dynamic Mechanical Analysis: The dynamic storage and loss modulus, G' and G', were determined using a Rheometrics ARES rheometer in oscillation mode. A $25 \mathrm{~mm}$ diameter cone-and-plate geometry was used for the test. Measurements were collected isothermally (at $160^{\circ} \mathrm{C}$ ) over a frequency range from 0.05 to $100 \mathrm{rad} / \mathrm{s}$. The strain amplitude of $5 \%$ used was within the linear viscoelastic range of the block copolymer. A nitrogen atmosphere was used to prevent sample degradation. This dynamic mechanical spectroscopy (Figure 4) demonstrates that G' at low frequencies is larger than G' and scales as $\omega^{0.5}$ rather than as $\omega^{2}$ as expected for a liquid. This solid-like behavior for a sample well above $\mathrm{Tg}$ is quite typical of an ordered block copolymer.

Typical Copolymerization of Ethylene and 5-Norbornen-2-yl Acetate: A metal reactor was loaded inside a glove box with $2(20 \mu \mathrm{mol} ; 2.00 \mathrm{~g}$ of $8.77 \mathrm{mM}$ solution in toluene), $\mathrm{Ni}(\mathrm{COD})_{2}(50 \mu \mathrm{mol} ; 2.5 \mathrm{~g}$ of $17.6 \mathrm{mM}$ solution in toluene), 5-norbornen-2-yl acetate (4.50 mmol; $3.00 \mathrm{~g}$ of $1.30 \mathrm{M}$ solution in toluene), and toluene (18.45 g) such that this solution mimicked the precise composition of the block copolymerization during the synthesis of the first block. The metal reactor was sealed inside the glove box and was attached to a vacuum/nitrogen line manifold. Ethylene was fed continuously into the reactor at $50 \mathrm{psi}$ and the pressurized reaction mixture was stirred at $20{ }^{\circ} \mathrm{C}$. Ethylene was vented after the desired time and acetone was added to quench the polymerization. The precipitated polymer was collected by filtration and dried under high vacuum overnight.

\section{Typical Block Copolymerization of Ethylene and 5-Norbornen-2-yl Acetate by}

Ethylene Pressure Variation: A metal reactor was loaded inside a glove box with 2 (20 $\mu \mathrm{mol} ; 2.00 \mathrm{~g}$ of $8.77 \mathrm{mM}$ solution in toluene), $\mathrm{Ni}(\mathrm{COD})_{2}(50 \mu \mathrm{mol} ; 2.50 \mathrm{~g}$ of $17.6 \mathrm{mM}$ solution in toluene), 5-norbornen-2-yl acetate $(4.50 \mathrm{mmol} ; 3.00 \mathrm{~g}$ of $1.30 \mathrm{M}$ solution in toluene), and toluene (18.45 g) were added to the reactor bottom, such that the total 
volume of the solution was $30 \mathrm{~mL}$. The metal reactor was sealed inside the glove box and was attached to a vacuum/nitrogen line manifold. 50 psi of ethylene pressure was added continuously to the reactor and the pressurized reaction mixture was stirred at 20 ${ }^{\circ} \mathrm{C}$ to allow formation of an NBA-rich copolymer block. At a specified time the ethylene pressure was increased to 1100 psi and the reaction was stirred for an additional specified time. Note: Care must be taken in the synthesis of the second block, since there are inherent dangers in high pressure polymerizations. These reactions should be performed only in high-pressure rated stainless steel reactors. A plexi-glass explosion-proof shield should be placed surrounding the reactor for additional safety. Polymer precipitate could be observed at the end of the reaction before the addition of acetone. Ethylene was vented to finish the reaction and acetone was added to quench the polymerization. The precipitated polymer was collected by filtration and dried under vacuum overnight.

Figure 1: GPC overlay of Block A and Final Block Copolymer (Table 1, Entry 4).

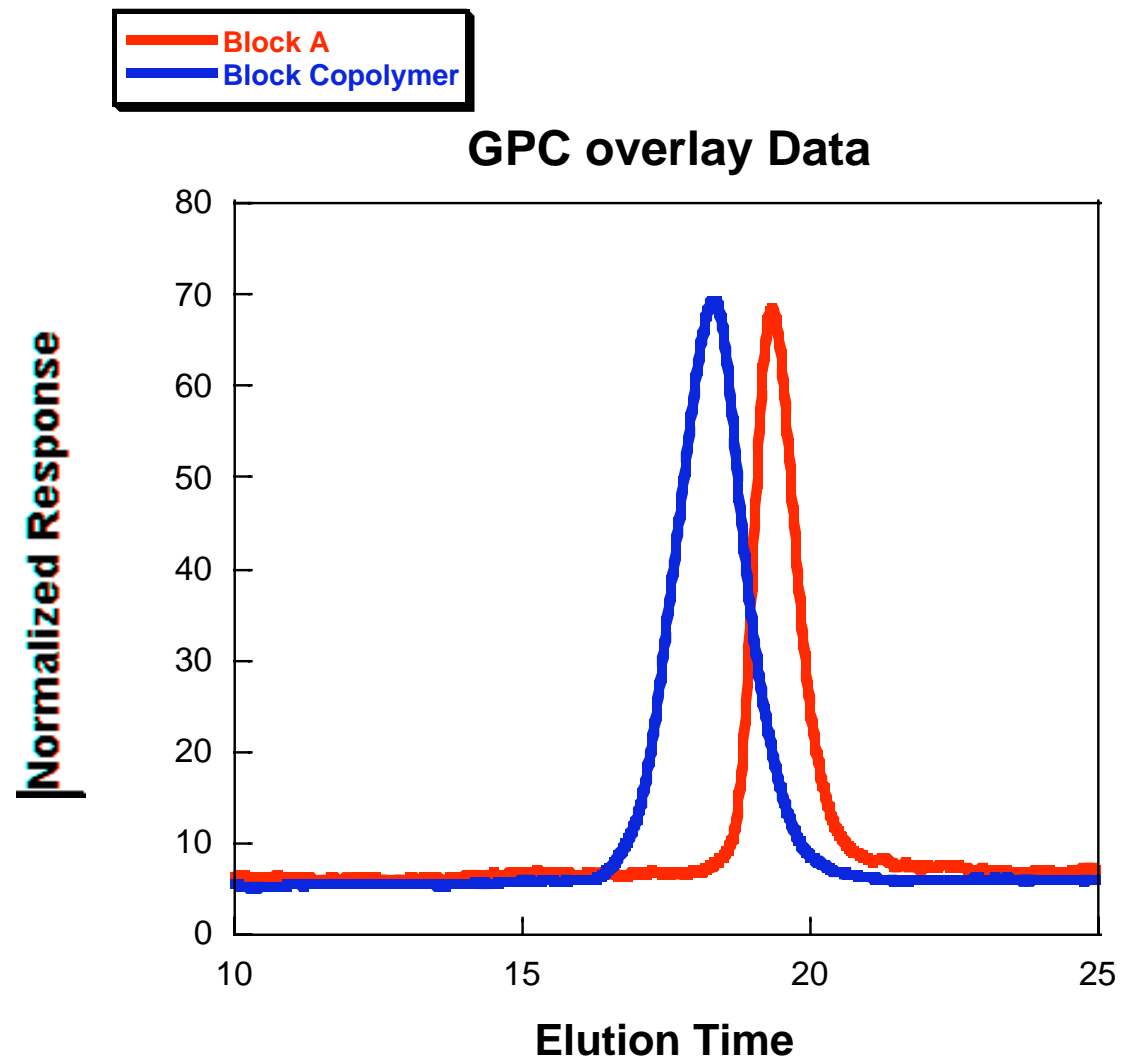


Figure 2: Relationship between ethylene pressure and comonomer incorporation.

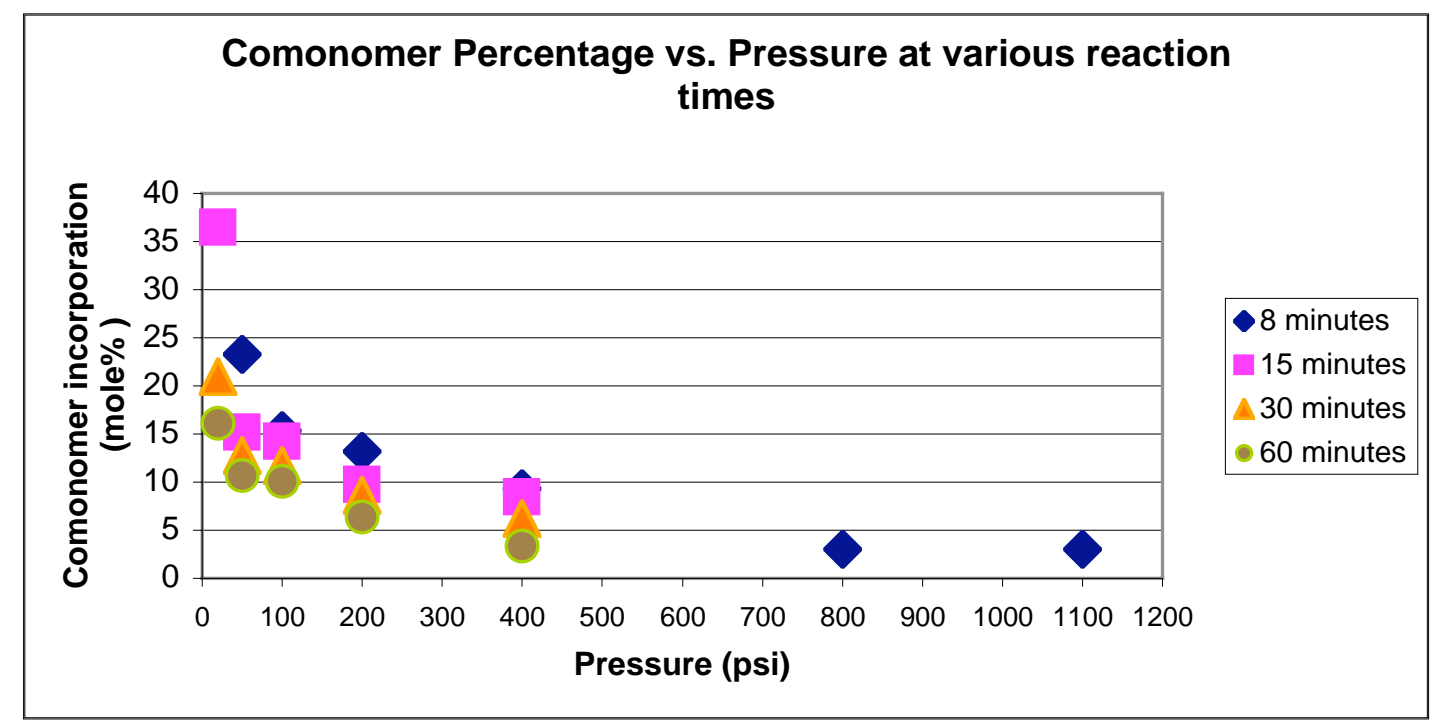


Figure 3. AFM images of microphase separated polymer samples.

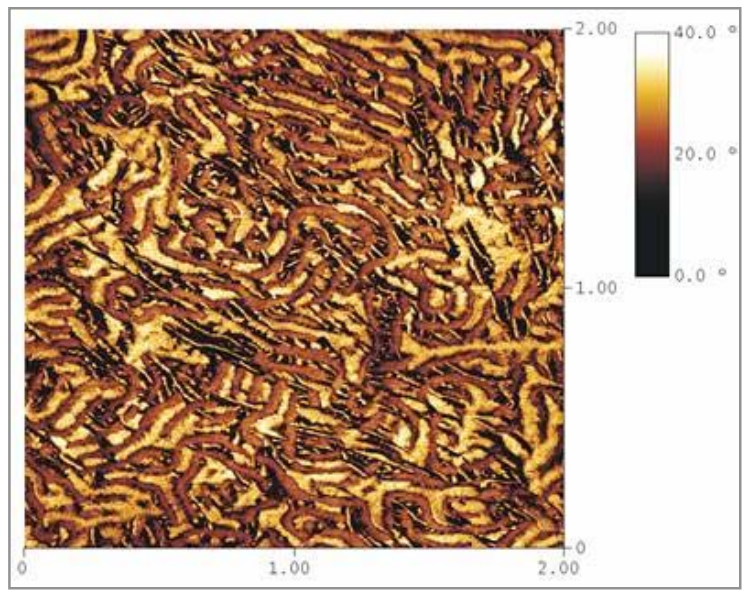

(a) Sample: entry 2, Table 1. X and Y scales are in micrometers.

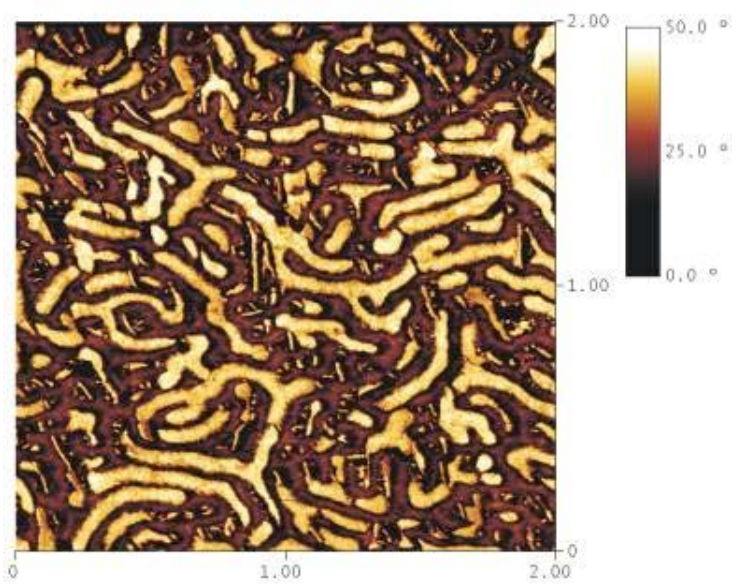

(b) Sample: entry 9, Table 1. X and Y scales are in micrometers. 
Figure 4: DMA Analysis of Entry 1, Table 1.

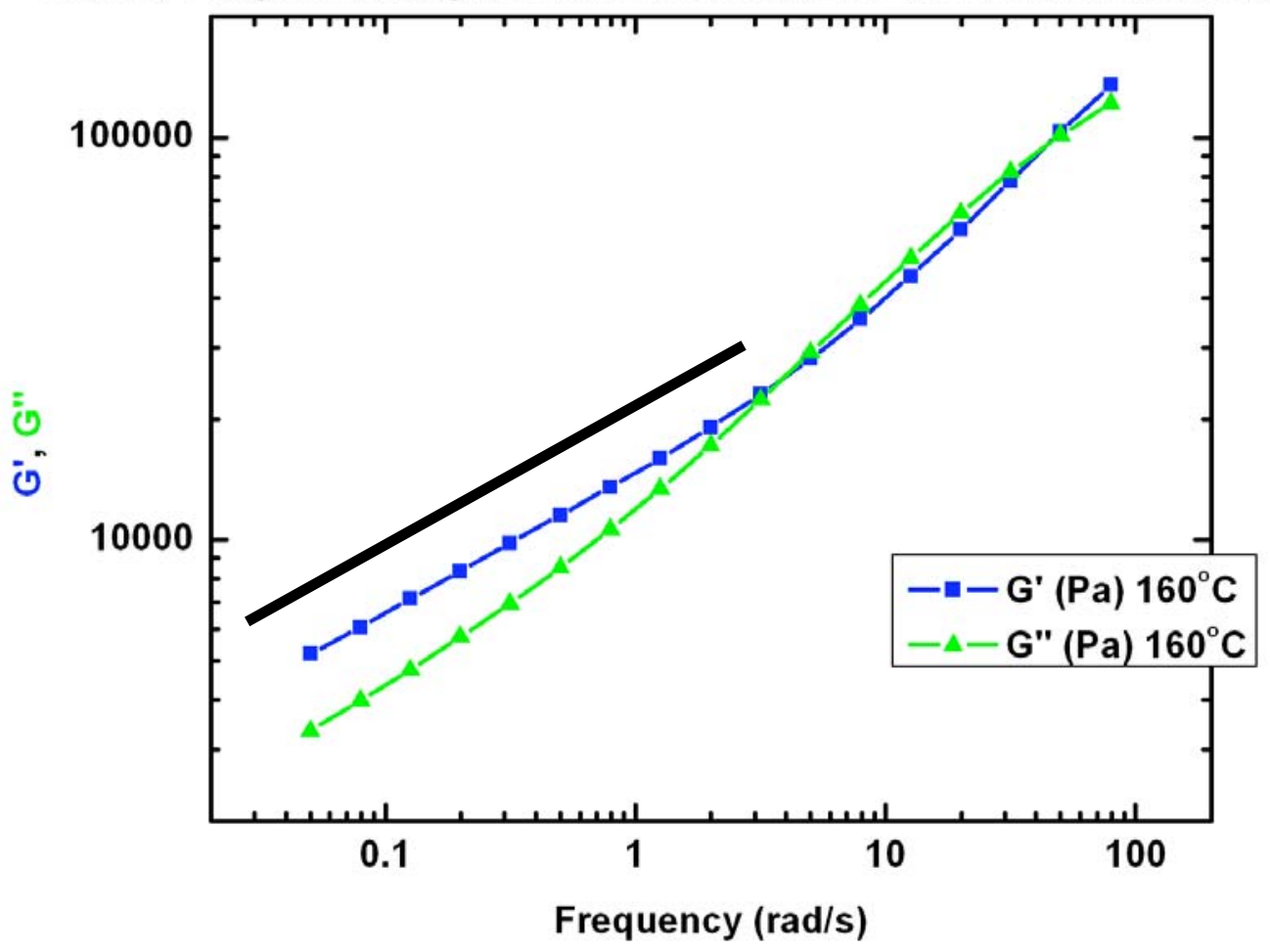

Figure 5: TEM micrograph of Entry 1, Table 1.

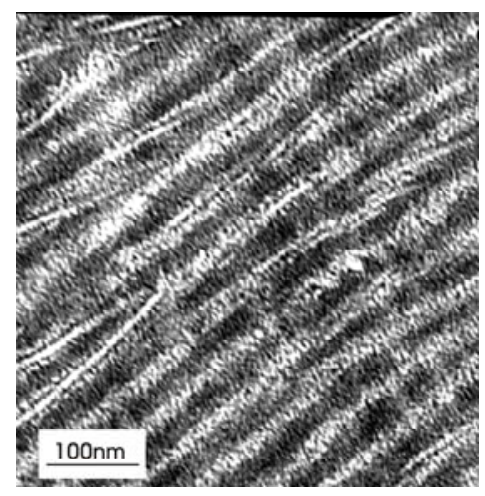

Transmission electron micrograph of Entry 1 with a PE weight fraction of 0.43 . The morphology is lamellar, where semicrystalline PE layers (light) alternate with amorphous copolymer layers. PE crystals in the PE lamellae are also clearly visible.

\section{Reference:}

${ }^{1}$ Lee, B. Y.; Bazan, G. C.; Vela, J.; Komon, Z. J. A.; Bu, X. J. Am. Chem. Soc. 2001, $123,5352$. 